\title{
Surface and Impurity Studies in ORMAK and ISX
}
R. J. Colchin
R. E. Clausing
L. C. Emerson
L. Heatherly
R. C. Isler 


\section{DISCLAIMER}

This report was prepared as an account of work sponsored by an agency of the United States Government. Neither the United States Government nor any agency Thereof, nor any of their employees, makes any warranty, express or implied, or assumes any legal liability or responsibility for the accuracy, completeness, or usefulness of any information, apparatus, product, or process disclosed, or represents that its use would not infringe privately owned rights. Reference herein to any specific commercial product, process, or service by trade name, trademark, manufacturer, or otherwise does not necessarily constitute or imply its endorsement, recommendation, or favoring by the United States Government or any agency thereof. The views and opinions of authors expressed herein do not necessarily state or reflect those of the United States Government or any agency thereof. 


\section{DISCLAIMER}

Portions of this document may be illegible in electronic image products. Images are produced from the best available original document. 


\section{Printed in the United States of America. Available from National Technical Information Service \\ U.S. Department of Commerce 5285 Port Royal Road, Springfield, Virginia 22161}

Price: Printed Copy $\$ 4.00$; Microfiche $\$ 3.00$

This report was prepared as an account of work sponsored by the United States Government. Neither the United States nor the Energy Research and Development Administration/United States Nuclear Regulatory Commission, nor any of their employees, nor any of their contractors, subcontractors, or their employees, makes any warranty, express or implied, or assumes any legal liability or responsibility for the accuracy, completeness or usefulness of any information, apparatus, product or process disclosed, or represents that its use would not infringe privately owned rights. 
Contract No. W-7405-eng-26

Fusion Energy Division

\title{
SURFACE AND IMPURITY STUDIES IN ORMAK AND ISX
}

R. J. Colchin, R. E. Clausing, L. C. Emerson,

L. Heatherly, and R. C. Isler

Date Published - February 1977

Presented at the International Symposium on Plasma Wall Interaction, Jïlich, Federal Republic of Germany, October 18-22, 1976.

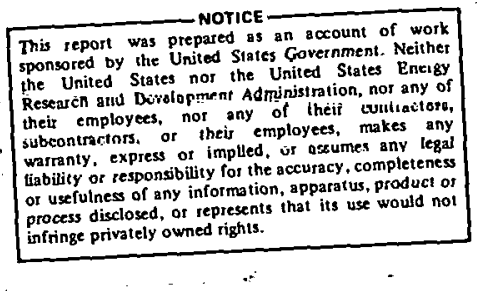

NOTICE This document contains information of a preliminary nature. It is subject to revision or curretion and therefore docs not represent a final report.

\author{
OAK RIDGE NATIONAL LABORATORY \\ Oak Ridge, Tennessee 37830 \\ operated by \\ UNION CARBIDE CORPORATION \\ for the \\ ENERGY RESEARCH AND DEVELOPMENT ADMINISTRATION
}


R. J. Colchin, R. E. Clausing, L. C. Emerson, L. Heatherly, and R. C. Isler

Oak Ridge National Laboratory Oak Ridge, Tennessee 37830, USA

\section{ABSTRACT}

The ORMAK vacuum liner is constructed of stainless steel overcoated with a thin platinum diffusion barrier and a final layer of gold. Gold was selected as the vacuum surface because it is chemically inert to the adsorption of common gases. However, gold surfaces do adsorb hydrocarbons, and carbon (along with oxygen) was the principal plasma contaminant during the first two years of ORMAK operation. Upon switching dischargecleaning gases from hydrogen to oxygen, carbion levels dropped until carbon is no longer a significant contaminant; residual hydrocarbons can now be controlled either by hydrogen or by oxygen discharge cleaning. The principal measured plasma contaminant in ORMAK is now oxygen. Samples taken from the ORMAK Iiner and analyzed by Auger electron spectroscopy reveal the presence of iron and oxygen. There is evidence from a SXAPS (Soft X-ray Appearance Potential Spectroscopy) probe of iron and. chromium diffusion from the stainless steel through the gold surface in spite of the platinum diffusion barrier. The iron and chromium provide surface oxidation sites, and SXAPS analysis shows that these metals exist as oxides.

In order to investigate tokamak impurity problems further, the ISX (Impurity Study Experiment) tokamak is presently under construction. It will provide a cleaner and more flexible vacuum system in which to conduct studies of surfaces and plasma impurities. The operating characteristics will be much the same as those of ORMAK (with ohmic heating) in terms of size, plasma current, and plasma temperature.

\section{INTRODUCTION}

Throughout the life of the ORMAK tokamak, Z eff has typically been $\geqslant 4$. Various modes of discharge cleaning have been employed in an attempt

\footnotetext{
* Research sponsored by the Energy Research and Development Administration under contract with the Union Carbide Corporation.
} 
to reduce impurities present through modification of wall conditions. As with other tokamaks, ORMAK discharge characteristics are quite sensitive to wall preparation. A summary of discharge cleaning and impurity experiments is given in the next section. A SXAPS (Soft $X$-ray Appearance Potential Spectroscopy) probe has been used to determine how surface conditions respond to discharge cleaning as well as to high-current tokamak discharges. A description of the SXAPS device is given in the third section, and results of ORMAK experiments are detailed in Sect.. 4 .

In order to expand and extend these impurity experiments, a new tokamak called ISX (Impurity Study Experiment) is being constructed. This device is aimed at providing a relatively clean and flexible vacuum system in which to perform studies of plasma-wall interactions and impurities. A general description of the ISX and anticipated experiments is given in Sect. 5 .

\section{DISCHARGE CLEANING AND PLASMA IMPURITIES IN ORMAK}

The ORMAK vacuum system consists of inner and outer vacuum chambers. Plasma discharges are formed in the inner chamber (liner), which is constructed of $304 \mathrm{~L}$ stainless steel overcoated with a thin $\left(\approx 500^{\circ}\right)$. layer of platinum and an outer $(\approx \mu \mathrm{m})$ layer of gold. It was intended that the platinum layer act as a barrier to diffusion of the stainless components through the gold film. Ion microprobe tests of similar material after it was baked for an hour at $300^{\circ} \mathrm{C}$ showed a marked decrease in surface impurities as compared with similar samples with no platinum barrier. 
Discharge cleaning was used during the last four years to condition the surface of the liner. Initially, cleaning discharges were run in hydrogen at the rate of $120 \mathrm{~Hz}$ with each pulse lasting about $500 \mu \mathrm{sec}$. Current-induced heating in the liner simultaneously caused a mild baking of the walls, at temperatures in the range $150-200^{\circ} \mathrm{C}$. During this type of cleaning only hydrogen spectral lines were observed, but carbon and oxygen were present in the normal tokamak discharges. In the last two years, similar-length cleaning discharges have been run using oxygen in addition to hydrogen. 2,3 The carbon concentration has fallen, and carbon is no longer a significant plasma contaminant. However, it is observed that the oxygen impurity level increases by nearly a factor of 2 after oxygen cleaning.

Recently, more powerful though less frequent cleaning discharges in hydrogen have been tried. Discharges with a peak current of $16 \mathrm{kA}$ and a safety factor $q=1$ are initiated at the rate of two/sec. Figure 1 gives a comparison of spectra in the vacuum ultraviolet region resulting from the new and old discharge-cleaning techniques. Oxygen, carbon, and nitrogen impurities are evident in the more powerful discharges. In the initial tests, residual carbon and nitrogen underwent marked decreases. during overnight cleaning, while the oxygen level decreased only slightly. The oxygen concentration during the normal tokamak discharges remained at the level observed prior to initiating the high-power, pulsed cleaning.

Spectroscopic measuremlitis show that regardless of the type of discharge cleaning, oxygen is now the dominant light impurity observed in the plasma; this result is consistent with the observation that water vapor is the principal contaminant detected by the residual gas analyzer. 

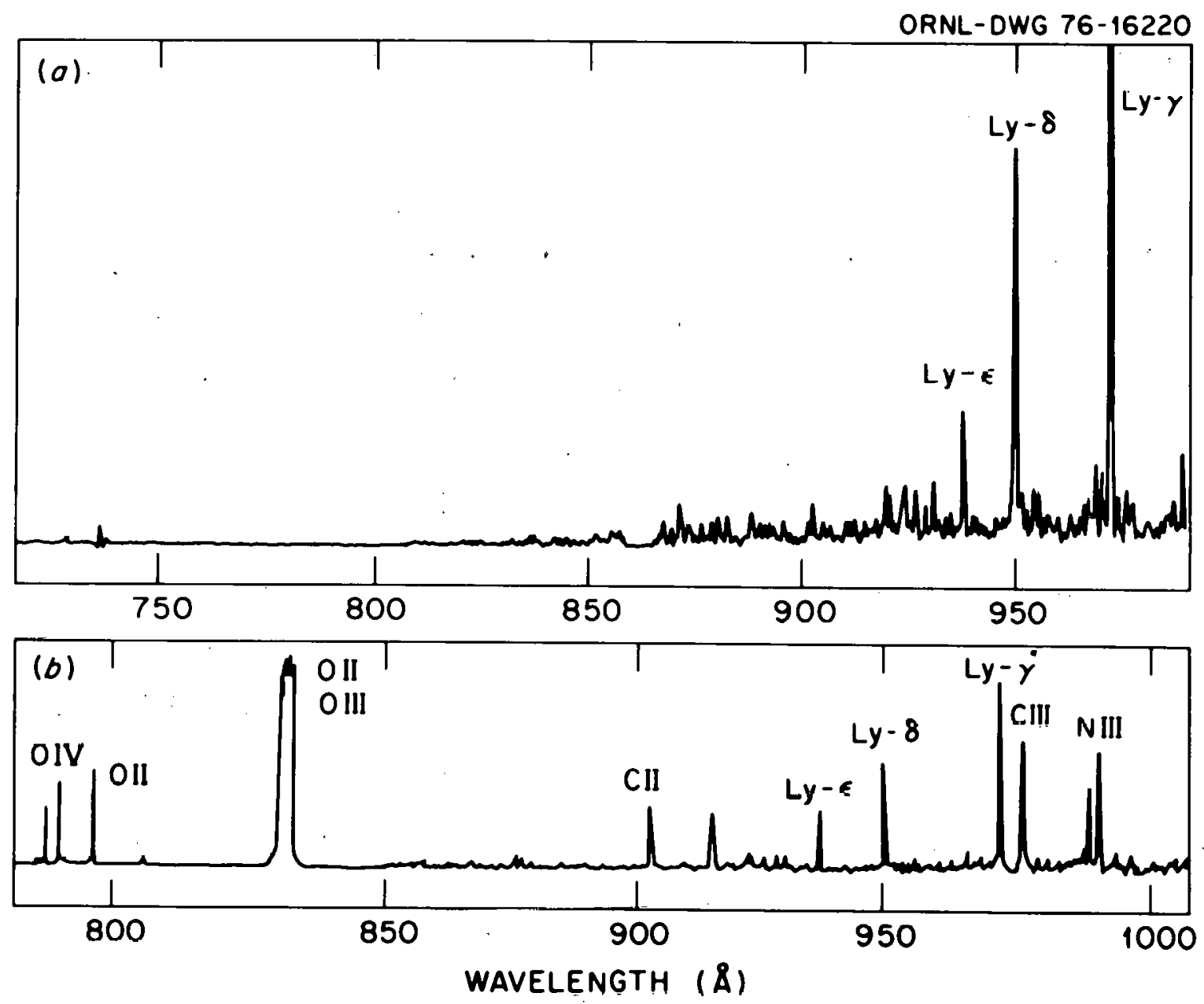

Fig. 1. (a) Partial spectrum of plasma observed during low-power 120-Hz discharges. No impurity lines are observed. The low-intensity fedlures are lines of molecular hydrogen. Signal strength is in arbitrary units. (b) Partial spectrum of plasma observed during high-power, pulsed discharge cleaning. The intensities of the impurity lines and of the hydrogen lines arc of the same maynltudc. Signai strength scales differ between (a) and (b). 
If carbon or nitrogen is observed at all in the plasma, their concentrations are less than $20 \%$ of the concentration of oxygen.

Iron is the most abundant heavy impurity which has been identified by spectral analysis, and its concentration is estimated to be no more than one-tenth the concentration of oxygen. The abundance of gold and tungsten (limiter material) remains uncertain; the wavelengths of lịnes from high ionization stages of these elements are not known, so that even their presence in the plasma cannot be verified. However, gold and tungsten could well be present as there are numerous unidentified lines. A typical vacuum ultraviolet spectrum is shown in Fig. 2.

Spectral lines with wavelengths longer than $50 \AA$ are superimposed on a band of "continuum" radiation. The origin of this radiation is unknown, but it may be attributed either to closely spaced lines from a heavy element (such as tungsten or gold) or to recombination radiation near the wall. In any case, this "continuum" radiation accounts for a significant fraction of the radiated power and of the electron energy loss.

Besides spectroscopy, three other techniques of determining $z_{\text {eff }}$ have been used: ${ }^{2}$ soft $x$-rays, plasma conductivity, and fast ion scattering. All impurity diagnostics have practical difficulties which lead to relatively large experimental errors; however, all methods give $z_{\text {eff }} \geqslant$ 4. Spatially resolved soft $x$-ray measurements have been made using a PIN diode array. These measurements, in which coronal equilibrium is assumed, indicate that liglit impuritics dominate at low currents and that heavy impurities become important in high-current discharges. Although we observe a gradual increase of impurities with time, there is no preferential accumulation at the center of the plasma. 


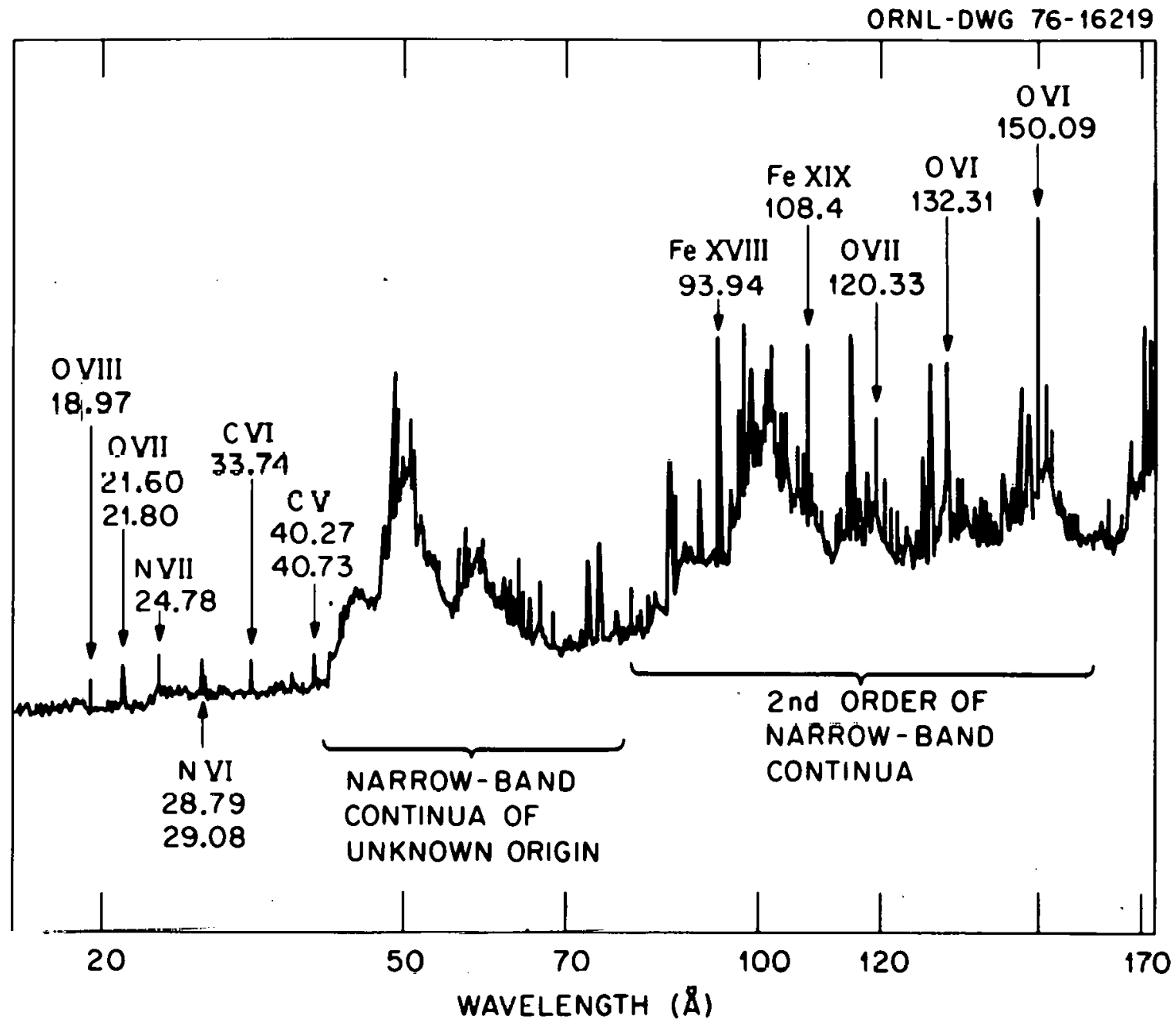

Fig. 2. Densitometer trace from $20 \AA$ to $170 \AA$ of spectra photographed during normal tokamak discharges. Most of the strong lines can be associated with ions of oxygen and iron, but several relatively intense features around $50 \AA$ are unidentified.

\section{SXAPS DESCRIPTION}

A SXAPS prohe has been used during the labl four months to evaluate ORMAK surface conditions. Since this method differs from the Auger analysis systems used on the Pulsator (QWAASS) ${ }^{4}$ and PLT (SAS) ${ }^{5}$ tokamaks, a brief description is given below.

A review of soft $x$-ray appearance potential spectrometry has been given by Park and Houston. ${ }^{6}$ The ORMAK SXAPS ${ }^{7}$ probe is shown schematically 
in Fig. 3. The surfaces which are analyzed lie on the faces of an eight-sided wheel. One face is exposed to normal plasma or to cleaning discharges and then rotated $180^{\circ}$ to face the filament. A variable high voltage is applied to the wheel, and electrons accelerated from the filament release soft $x$ rays from surface atoms. These soft $x$ rays correspond to core-level excitations along with a bremsstrahlung background. Soft $x$ rays falling on the gold-coated photocathode create

ORNL-OWG 75-11604

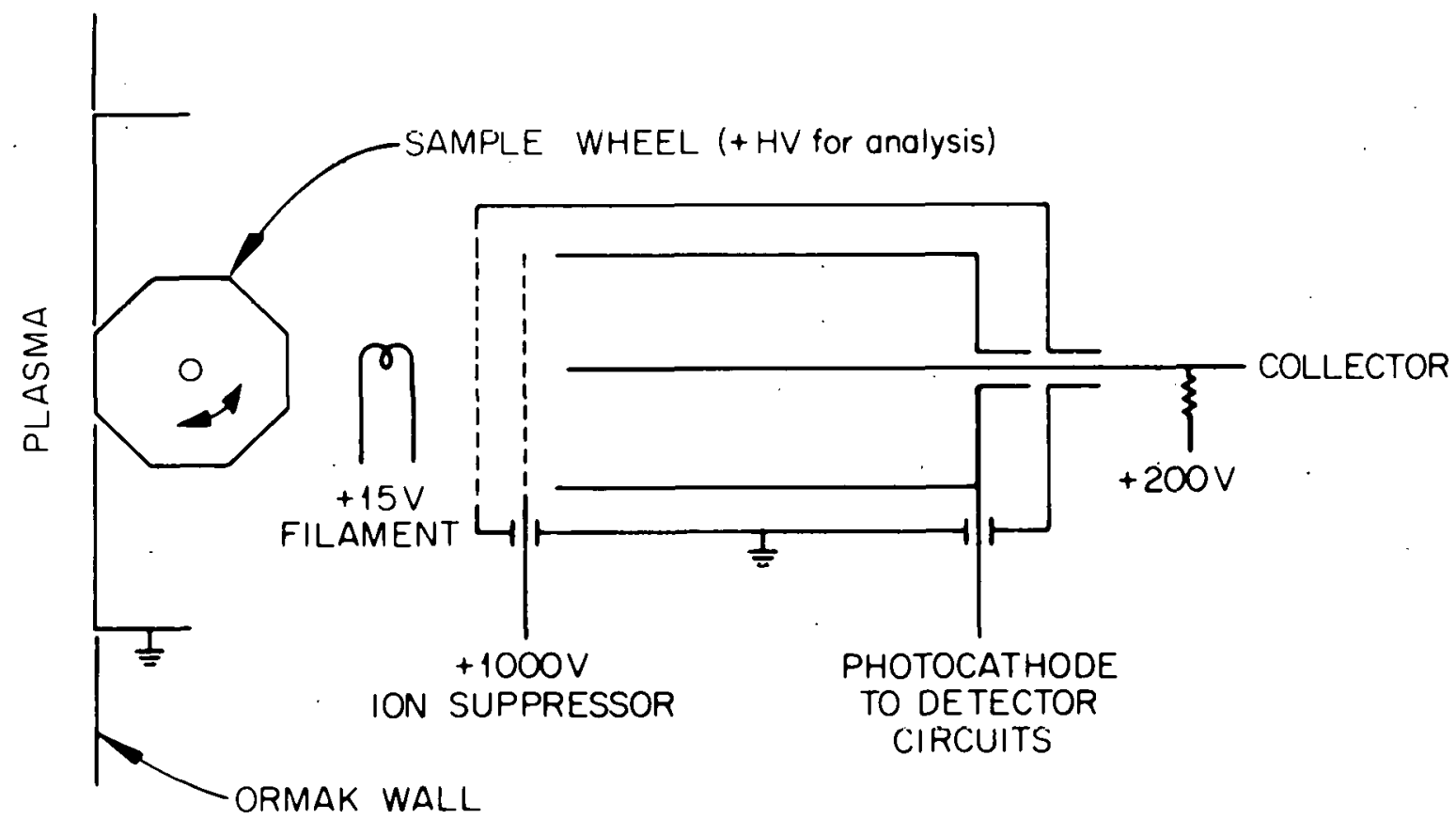

\section{SXAPS Probe for ORMAK}

Fig. 3. Schematic of SXAPS probe as configured for use in ORMAK. The sample wheel is turned by a mechanical linkage. Data described in this paper was taken with the ion suppressor and photocathode held at ground potential, and the signal was taken from the collector. 
secondary electrons which are attracted to the collector wire. In order to separate sharp lines produced by core-level excitations from the bremsstrahlung, the collector current signal is twice differentiated.

Soft $x$-ray appearance potential spectroscopy has not undergone as extensive a development as has AES (Auger Electron Spectroscopy) and is not a quantitative measurement technique. As pointed out by Musket, ${ }^{8}$ the amplitude and detailed shape of the SXAPS spectrum is sensitive to chemical binding and hence gives chemical information not obtainable from AES. SXAPS can detect most of the tokamak surface contaminants such as stainless steel $(\mathrm{Fe}, \mathrm{O}, \mathrm{Ni}$, and $\mathrm{Cr}$ ) and carbon, but is insensitive to gold. It has been our experience that even though SXAPS does not give quantitative estimates of surface coverage, it provides a very convenient monitor of liner surface conditions.

Figure 4 shows the SXAPS spectra of a stainless steel sample taken with a test probe at the ORMAK site. SXAPS is quite sensitive to iron, chromium, and nickel and somewhat less sensitive to carbon and oxygen, although carbon contamination is easily detected (as may be seen in Fig. 4). We find that contaminated specimens exhibit noisier spectra than do clean specimens. 
ORNL-OWG 76-15239

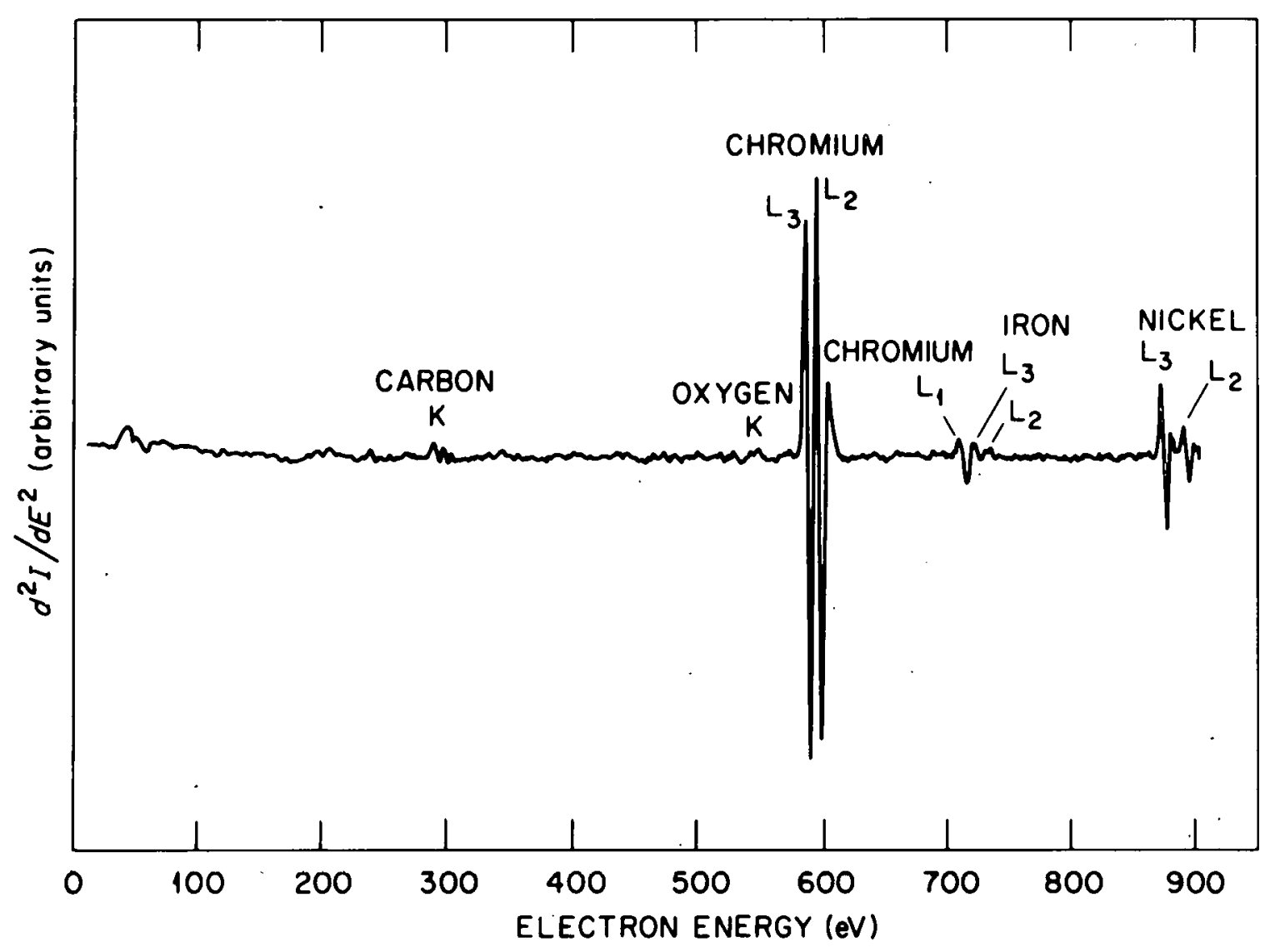

Fig. 4. SXAPS test spectrum of a stainless steel sample. This data was taken with a test probe at the ORMAK site.

\section{SXAPS RESULTS}

Data have been taken using two different eight-sided wheel, both of which were made of stainless steel and coated with gold and platinum as described in Sect. 2. The second wheel contained a much thicker platinum layer than the first. One of the eight sides of each wheel was bare stainless steel, and a two-mil-thick gold foil was welded to a face of the second wheel.

Before discharge cleaning the first wheel, only carbon was observed on the gold faces. After discharge cleaning in hydrogen over a weekend, 
the components of stainless steel appeared on all faces. Similar contamination has been observed on liner samples taken from ORMAK and analyzed by AES. ${ }^{7}$ A typical spectrum from the stainless steel face is shown in Fig. 5. The two peaks following the initial oxygen $K$ peak are probably due to surface plasmon oscillations. 9 According to Houston and Park, the peak following the chromium $L_{2}$ peak appears as the chromium becomes oxidized and thus gives chemical information. The relative height of this peak did not change either with discharge cleaning or with normal plasma discharges, indicating that the amount of $\mathrm{Cr}_{2} \mathrm{O}_{3}$ remained

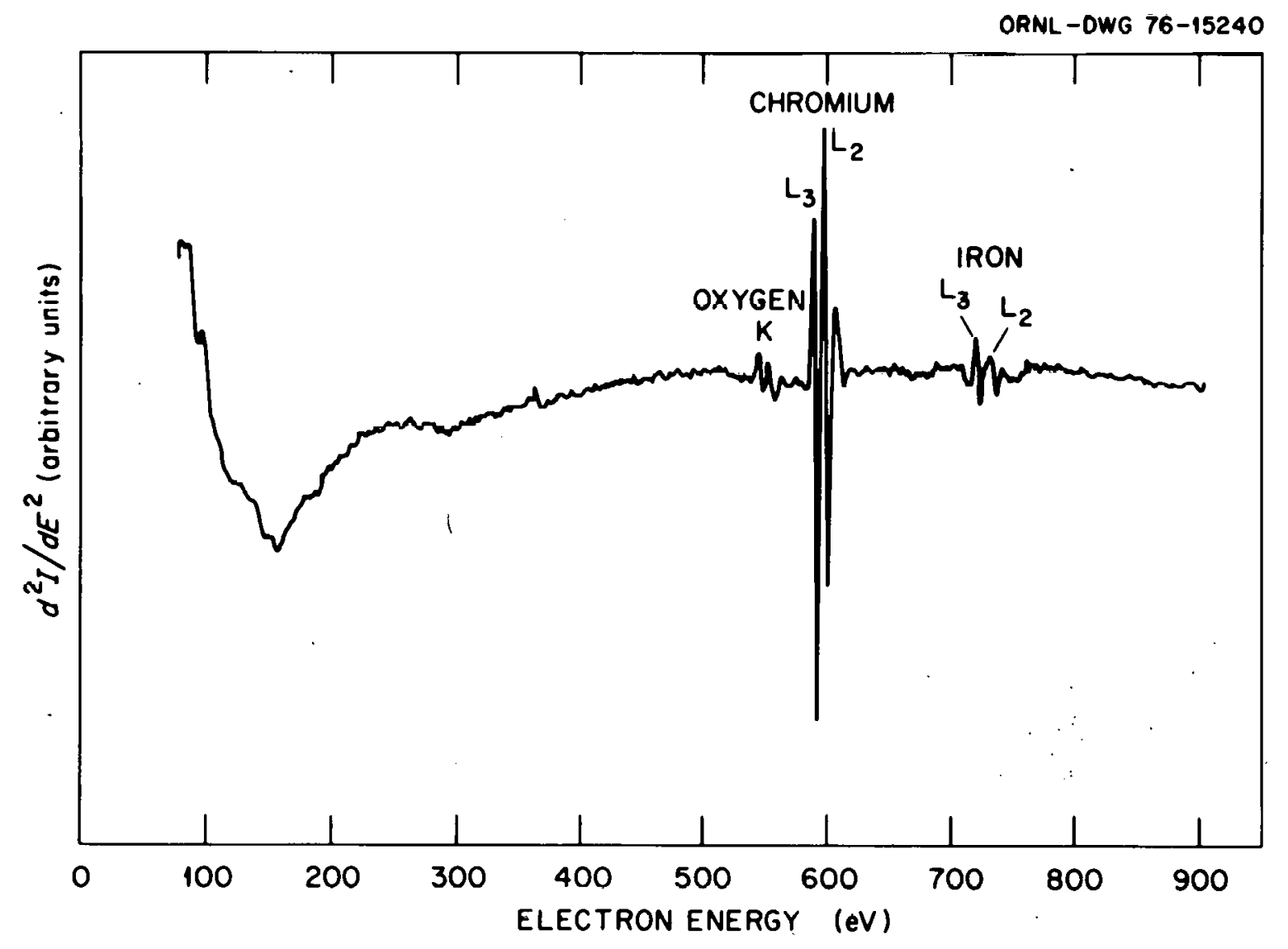

Fig. 5. SXAPS spectrum of the stainless steel face of the ORMAK probe. This face had been exposed to several days of both discharge cleaning and normal tokamak discharges. The peak at $364 \mathrm{eV}$ is due to calcium. 
constant. Likewise, the shape and height of the iron $L_{2}$ peak is sensitive to oxidation, the peak becoming broader and shorter as $\mathrm{Fe}_{3} \mathrm{O}_{4}$ and $\mathrm{Fe}_{2} \mathrm{O}_{3}$ are formed. 10 The SXAPS spectra observed in ORMAK were similar to those of Ref. 10 for oxidized iron. The small, unlabeled peak at $364 \mathrm{eV}$ is due to calcium $L_{3}$ and $L_{2}$ transitions. The spectrum of Fig. 5 was taken after overnight discharge cleaning with hydrogen gas. Similar spectra were observed after oxygen discharge cleaning, except the oxygen peaks were larger and not as clearly separated.

For all SXAPS experiments the current to the sample wheel was fixed at $5 \mathrm{~mA}$ (at voltages above $200 \mathrm{~V}$ ). This current was sufficient to polymerize residual hydrocarbons and cause a buildup of carbon on the wheel surface which we bombarded. This buildup of carbon is illustrated for a series of spectra in Fig. 6. The first spectrum, labeled (a), was taken after the stainless steel face had been discharge cleaned overnight in hydrogen. Spectrum (b) was taken 25 min after the first spectrum and shows signals from carbon starting to appear above the noise; the chromium and iron peaks simultaneously became smaller as the surface was covered by carbon. In spectrum (c), taken $25 \mathrm{~min}$ after (b), carbon is quite evident, while the other peaks have shrunk still further. After discharge cleaning overnight the carbon is no longer evident and the chromium and iron peak heights have been restored, as may be seen in spectrum (d). Results using the second wheel were similar to those using the first. Before discharge cleaning all faces were badly contaminated by carbon. The carbon disappeared upon exposure to discharge cleaning in hydrogen overnight, but it remained on unexposed faces. After four days of discharge cleaning, chromium appeared on the wheel faces that were 


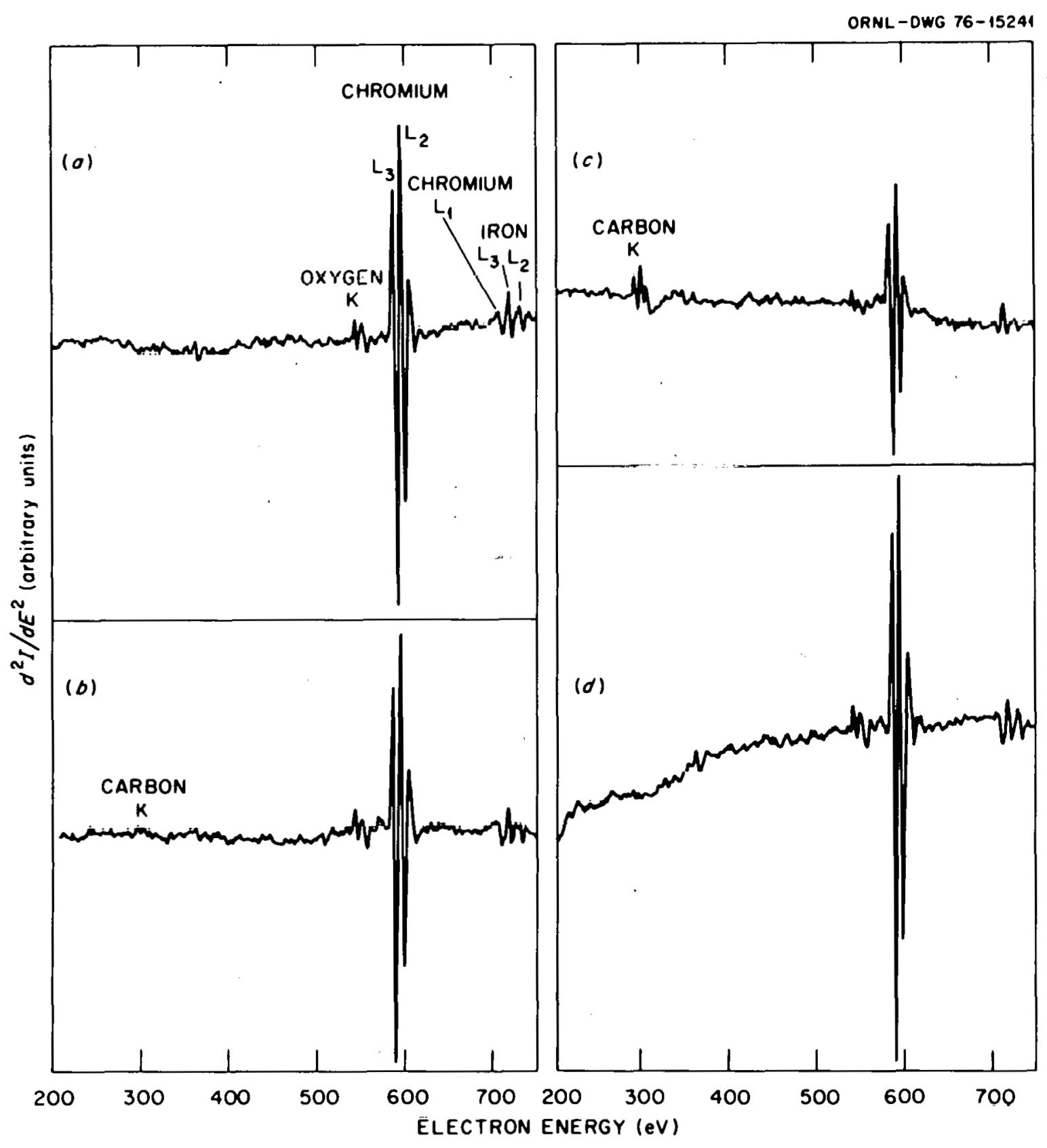

Fig. 6. Comparison of SXAPS spectra showing electron-induced adsorption of carbon on the stainless steel sample wheel face as a function of bombardment time. Spectrum (a) was taken after overnight discharge cleaning using $\mathrm{H}_{2}$ gas, (b) was taken 25 min after (a), and spectrum (c) was taken $25 \mathrm{~min}$ after (b). Spectrum (d) was taken after the face was again exposed to overnight discharge cleaning in $\mathrm{H}_{2}$. 
vacuum-coated with gold but not on the face covered with gold foil. No clear evidence of any contamination (other than hydrocarbon) was observed on the foil-covered face in over two weeks of operation. This implies that gold does provide a clean vacuum surface if it is applied in sufficiently thick layers.

\section{ISX (IMPURITY STUDY EXPERIMENT) TOKAMAK}

The ISX tokamak' 1 is being built as a joint project between the 0ak Ridge National Laboratory and General Atomic Company. This experiment will be dedicated to continuing and broadening the scope of the surface and plasma impurities studies presently initiated in ORMAK. Construction is under way, and experiments are scheduled to begin in the spring of 1977.

ISX is an iron-core tokamak of simple basic design; it is slightly larger than ORMAK. Toroidal field coils are rectangular and are joined so that the top of each coil can be removed. Ohmic heating and vertical field coils are wound on fiberglass cylinders encircling the central iron core. When the coil tops and the upper leg of the iron core are removed, the vacuum chamber is free to be removed vertically from the tokamak. This makes possible the easy interchange of plasma chambers. The estimated turnaround time is two weeks, working two shifts a day. Another consequence of simple design is large diagnostic access.

Basic machine parameters are listed in Table I. Plasma parameters are based on values routinely obtained in ORMAK. The vacuum chamber, shown in Fig. 7 , is of all-metal $304 \mathrm{~L}$ stainless steel construction. The pumping system is a combination of cryosorption and turbomolecular pumps; 
Table I. ISX parameters

Toroidal field

Transformer flux swing

Ultimate vacuum pressure

Major radius

Minor radius

Plasma current $(q=5)$

Central electron temperature

Central ion temperature

Shot repetition rate

Flat (equilibrium) current duration
$18 \mathrm{kG}$

$0.9 \mathrm{~V}-\mathrm{sec}$

$2 \times 10^{-9}$ torr

$93 \mathrm{~cm}$

$26 \mathrm{~cm}$

$150 \mathrm{kA}$

$800-1800 \mathrm{eV}$

300-500 eV

1 per minute

$250 \mathrm{msec}$

ORNL-DWG 76-15242R

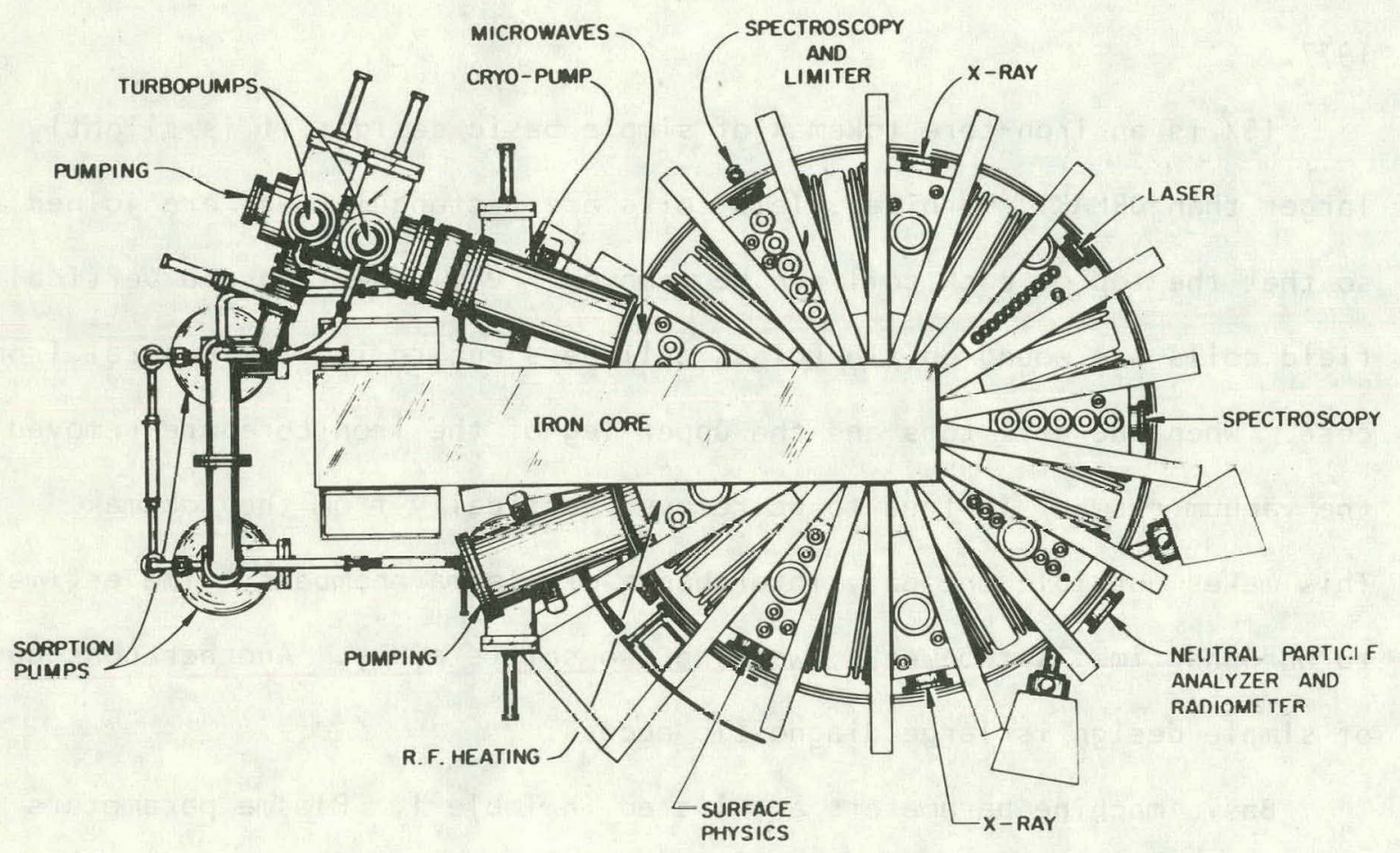

Fig. 7. ISX vacuum chamber and pumping system as viewed from above. Sorption pumps will be used for rough pumping. High vacuum will be maintained by a combination of turbomolecular pumps and cryosorption pumps. 
no pumps using oil will be used. Assuming an outgassing rate of $10^{-11}$ torr $-\ell / \mathrm{cm}^{2}-\mathrm{sec}$, the ultimate pressure should lie in the low $10^{-9}$ torr range. Discharge cleaning, titanium evaporation, and baking to $400^{\circ} \mathrm{C}$ will be used to achieve and maintain a low outgassing rate.

The ISX experimental program will be centered around surface-impurity studies and the transport and control of plasma impurities. Surface experiments will include detailed tests of various cleanup techniques, initially using the stainless steel vacuum chamber shown in Fig. 7 . These studies will be later extended to other materials, such as low-z walls and walls made from refractory materials. Initial plasma studies will involve a test of the impurity flow reversal scheme proposed by ohkawa. 12 Later studies will focus on plasma impurity transport and impurity accumulation.

\section{SUMMARY}

The ORMAK vacuum liner surface has undergone a continual evolution. The gold surface was initially contaminated by hydrocarbons. After oxygen discharge cleaning, carbon no longer was a significant contaminant. Residual hydrocarbons can now be controlled either by hydrogen or oxygen discharge cleaning. Iron oxides now appear on the liner surface, and SXAPS results indicate the iron may have originated by diffusion through the $-1 \mu m$-thick gold surface coating. Oxygen is the main light ion contaminant of the plasma, and iron is the major identifiable heavy contaminant.

A new tokamak, ISX, is being constructed to study wall and impurity problems in more detail. ISX is slightly larger than ORMAK and features 
an ultrahigh vacuum system for surface studies and ample diagnostic access for plasma impurity experiments. Operation is scheduled to begin in the spring of 1977.

\section{ACKNOWLEDGMENTS}

We would like to acknowledge the ORMAK Group for machine operation, especially P. H. Edmonds for design and operation of the high-current discharge cleaning circuits and G. L. Jahns for results of residual gas analysis. Those responsible for isx include T. C. Jernigan, K. H. Burrell, and the engineering staff of Union Carbide Corporation Nuclear Division. We would like to thank L. A. Berry and J. F. Clarke for their continuing support in carrying out experiments. 


\section{REFERENCES}

I. R. J. Colchin, L. A. Berry, G. R. Haste, G. G. Kelley, J. F. Lyon, J. R. McNally, M. Murakami, R. V. Neidigh, J. E. Simpkins, and W. R. Wing, "Wall Conditions in ORMAK," J. Nucl. Mater. 53, 25 (1974).

2. R. J. Colchin, C. E. Bush, G. L. Jahns, J. F. Lyon, M. Murakani, R. V. Neidigh, and D. L. Shaeffer, "Impurity and Surface Studies in ORMAK," to be published in J. Nucl. Mater. 63 (1976).

3. R. E. Clausing, L. C. Emerson, L. Heatherly, R. J. Colchin, and J. C. Twichell, "Measurement and Modification of First-Wall Surface Composition in the Oak Ridge Tokamak (ORMAK)," J. Vac. Sci. Technol. 13, $437(1976)$.

4. Ph. Staib and G. Staudenmaier, "Wall Analysis and Impurities in Pulsator 1," to be published in J. Nucl. Mater. 63 (1976).

5. H. F. Dylla and S. A. Cohen, "Changes in Surface Conditions with First Plasma in The Princeton Large Torus (PLT)," to be published in J. Nucl. Mater. 63 (1976).

6. F. L. Park and J. E. Houston, "Soft X-ray Appearance Potential Spectroscopy," J. Vac. Sci. Technol. 11, I (1974).

7. R. E. Clausing, L. C. Emerson, L. Heatherly; and R. J. Colchin, "Surface Impurities and 'Clean-up' Techniques in ORMAK," to be published in J. Nucl. Mater. 63 (1976).

8. R. G. Musket, "Direct Comparison of Auger Electron Spectroscopy with Appearance Potential Spectroscopy," J. Vac. Sci. Technol. 9, 603 (1972).

9. J. E. Houston and R. L. Park, "Effect of Oxygen on the Soft X-ray. Appearance Potential Spectrum of Chromium," J. Chem. Phys. $\underline{55}$, $4601(1971)$. 
10. K. N. Ramachandran and C. D. Cox, "Investigation of Surface Oxide Layers by X-ray Appearance Potential Spectroscopy," J. Electrochem. Soc. $121,673(1974)$.

11. R. J. Colchin and T. C. Jernigan, "ISX - A Tokamak for Surface and Impurities Studies," to be published in J. Nucl. Mater. 63 (1976).

12. K. H. Burrell and T. Ohkawa, "Method of Controlling Impurity Transport,". paper presented at the International Symposium of Plasma Wall Interaction, Julich, w. Germany, October 18-2.2, 1976. 


\section{INTERNAL DISTRIBUTION}

1. B. R. Appleton

2. C. F. Barnett

3. L. A. Berry

4. C. E. Bush

5. J.F. Clarke

6. R. E. Clausing

7. R. J. Colchin

8. J. L. Dunlap

9. P. H. Edmonds

10. R. C. I sler

11. G. L. Jahns

12. T. C. Jernigan

13. G. G. Kelley

14. J. F. Lyon

15. C. J. McHargue

16. 0. B. Morgan

17. M. Murakami
18. R. V. Neidigh

19. G. H. Neilson

20. V. K. Paré

21. D. Steiner

22. J. 0. Stiegler

23. D. W. Swain

24. J. R. Weir

25. J. B. Wilgen

26. W. R. Wing

27-28. Central Research Library

29. Document Reference Section

30-31. Laboratory Records Department

32. Laboratory Records, ORNL-RC

33. Patent Office

34. Fusion Energy Division Library

35. Fusion Energy Division Reports Office

\section{EXTERNAL DISTRIBUTION}

36. E. G. Apgar, Francis Bitter National Magnet Laboratory, Massachusetts Institute of Technology, Bldg. NW-14, Rm. 2225, Cambridge, MA 02139

37. R. Behrisch, Max-Planck-Institut für Plasmaphysik, D-8046 Garching bei München, West Germany

38. C. M. Braams, Fom-Instituut voor Plasma-Fysica, Rijnhuizen, Jutphaas, The Netherlands

39. A. M. Budker, Nuclear Physics Institute, Siberian Academy of Sciences, Novosibirsk 90 , U.S.S.R.

40. Prof. Piero Caldirola, Laboratorio di Fisica del Plasma ed Electtronica, Quantistica del C.N.R., Via Celoria, 16, 20133 Milano, I taly

41. Department of Nuclear Engineering Sciences, 202 Nuclear Science Center, University of Florida, Gainesville, FL 32611

42. Centre de Recherches en Library, Physique des Plasmas, 21 Avenue des Bains, 1007 Lausanne, Switzerland

43. S. A. Cohen, Plasma Physics Laboratory, Princeton University, P.0. Box 451, Princeton, NJ 08540

44. T. Consoli, Centre d'Etudes Nucleaires de Grenoble, Avenue des Martyrs-38-Grenoble, Republic of France

45. N. A. Davies, Tokamak Systems Branch, Division of Magnetic Fusion Energy Research, Mail Station G-234, Energy Research and Development Administration, Washington, DC 20545

46. S. 0. Dean, Office of Confinement Systems, Division of Magnetic Fusion Energy, Mail Station G-234, Energy Research and Development Administration, Washington; DC 20545

47. Director, Technical Library, Defense Atomic Support Agency, Sandia Base, Albuquerque, NM 87115 
48. A. M. Dupas, Documentation S.I.G.N., Department de la Physique due

Plasma et de la Fusion Controlee, Association EURATOM-CEA sur la Fusion, Centre d'Etudes Nucleaires, BP 85 Centre du Tri, 38041 Grenoble CEDEX, France

49. H. F. Dylla, Plasma Physics Laboratory, Princeton University, P.0. Box 451, Princeton, NJ 08540

50. 0. C. Eldridge, Physics Department, the University of Tennessee, Knoxville, TN 37916

51. H. P. Eubank, Plasma Physics Laboratory, Princeton University, P.0. Box 451, Princeton, NJ 08540

52. C. R. Finfgeld, Development and Technology, Division of Magnetic Fusion Energy, Mail Station G-234, Washington, DC 20545

53. H. K. Forsen, Exxon Nuclear Co., Inc., 777 106th Avenue, NE, Bellevue, WA 98004

54. T. K. Fowler, Lawrence Radiation Laboratory, University of California, P.0. Box 808, Livermure, CA 94551

55. H. P. Furth, Plasma Physics Laboratory, Princeton University, P.0. Box 451, Princeton, NJ 08540

56. R. W. Gould, Professor, Electrical Engineering and Physics, Bldg. 116-81, California Institute of Technology, Pasadena, CA 91109

57. Harold Grad, Courant Institute, New York University, 251 Mercer Street, New York, NY 10012

58. H. R. Griem, Department of Physics, University of Maryland, College Park, MD 20742

59. V. M. Gusev, I. V. Kurchatov Atomic Energy Institute, Moscow, U:S.S.R.

60. 1. Guerdsiteli, Physico-Technical Institute, Georgian Academy of Sciences, Sukhumi, U.S.S.R.

61. A. M. Hamende, International Centre for Theoretical Physics, Trieste, Italy

62. Research Laboratory of Electronics, Attention J. Hewitt, Massachusetts Institute of Technology, Document Room 36-412, Cambridge, MA 02139

63. Toru Hiraoka, Japan Atomic Energy Research Institute, Tokai, Ibaraki, Japan

64. P. Hubert, Service de Recherches sur la Fusion Controlee, Centre d'Etudes Nucleaires, Fontenay-aux-Roses (Seine), France

65. K. Husimi, Institute for Plasma Physics, Nagoya University, Nagoya, Japan

66. D. W. Ignat, Tokamak Systems Branch, Division of Magnetic Fusion Energy, Mail Station G-234, Energy Research and Development Administration, Washington, DC 20545

67. M. S. Kaminsky, Argonne National Laboratory, 9700 S. Cass Avenue, Arguinrie, IL 60439

68. E. E. Kintner, Director, Division of Magnetic Fusion Energy, Mail Station G-234, Energy Research and Development Administration, Washington, DC 20545

69. E. Komar, D. V. Efremov Scientific Research Institute of ElectroPhysical Apparatus, Leningrad, U.S.S.R.

70. Suuji Komiya, ULVAC Corporation, 2500 Hagisono, Chigasaki KanagawaPref., Japan

71. H. E. Knoepfel, Laboratorio Gas Ionizzati, C.P. 65, 00044 Frascati (Rome), Italy 
72. Librarian, Physical Sciences Laboratory, P.0. Box 6, Stoughton, WI 53589

73. Librarian, Institute for Plasma Physics, 8046 Garching be i München, Federal Republic of Germany

74. Librarian, Culham Laboratory, UK Atomic Energy Authority, Abingdon, Berkshire, England

75. Plasma Physics Library, Plasma Physics Laboratory, Princeton University, P.0. Box 451, Princeton, NJ 08540

76. M. J. Lubin, Department of Mechanical and Aerospace Sciences, University of Rochester, Rochester, NY 14627

77. G. M. MCCracken, APET Division, Culham Laboratory, Bldg. 5, Abingdon, Oxfordshire, England

78. G. H. Miley, Professor, Department of Nuclear and Electrical Engineering, 214 Nuclear Engineering Laboratory, Urbana, IL 61801

79. R. G. Musket, Sandia Laboratories, Livermore, CA 94550

80. B. Navinsek, Institut Jozef Stefan, P.0. Box 199, Ljubljana, Yugoslavia

81. T. Ohkawa, General Atomic Company, P.0. Box 81608, San Diego, CA 92138

82. D. Palumbo, Directorate General for Research and Training, EURATOM, 51 Rue Belliard, Brussels 5, Belgium

83. Plasma Laboratory Reading Room, Massachusetts Institute of Technology, Room 20A-222, Cambridge, MA 02139

84. F. Prevot, Chef du Service de Confinement des Plasmas, C.E.A., B.P. No. 6, 92 Fontenay-aux-Roses, France

85. M. S. Rabinovich, Lebedev Institute of Physics, Academy of Sciences of the U.S.S.R., Leninsky Prospect 53, Moscow, U.S.S.R.

86. Center for Plasma Physics and Thermonuclear Research, University of Texas, 330 Physics Building, Austin, TX 78712

87. Research Information Center, Institute of Plasma Physics, Nagoya University, Nagoya, Japan

88. F. L. Ribe, Los Alamos Scientific Laboratory, P.0. Box 1663, Los Alamos, NM 87544

89. D. J. Rose, Massachusetts Institute of Technology, Room 24-210, Cambridge, MA 02139

90. R. Rye, Sandia Laboratories, P.0. Box 5800, Albuquerque, NM 87115

91. J. N. Smlth, General Atomic Co., P.0. Bux 81608, San Diego, CA 92138

92. Ph. Staib, Max-Planck-Institut für Plasmaphysik, D-8046 Garching be $i$ München, West Germany

93. G. Staudenmaier, Max-Planck-Institut für Plasmaphysik, D-8046 Garching bei München, West Germany

94. D. L. Styris, Battelle Pacific Northwest Laboratories, P.0. Box 999, Richland, WA 99352

95. R. Taylor, Department of Physics, University of California at Los Angeles, Los Angeles, CA 90024

96. Eugene Velikov, Thermonuclear Laboratory, Kurchatov Institute of Atomic Energy, 46 Ulitsa Kurchatova, Post Box 3402, Moscow, U.S.S.R.

97. H. Vernickel, Max-Planck-Institut für Plasmaphysik, D-8046 Garching bei München, West Germany

98. F. Waelbroeck, Institut für Plasmaphysik - KFA, Postfach 1913, D5l7 Jülich 1, GMBH, West Cermany 
99. H. H. Woodson, Department of Electrical Engineering, University of Texas at Austin, Austin, TX 78712

100. K. M. Zwilsky, Development and Technology, Division of Magnetic Fusion Energy, Mail Station G-234, Energy Research and Development Administration, Washington, DC 20545

101. Research, and Technical Support Division, Oak Ridge Operations, Energy Research and Development Administration, P.0. Box E, Oak Ridge, TN 37830

102-128. Technical Information Center, P.0. Box 62, 0ak Ridge, TN 37830 